\title{
A PRODUÇÃO CIENTÍFICA SOBRE TERAPIA OCUPACIONAL: O SILENCIAMENTO DA RELAÇÃO TRABALHO-SAÚDE
}

\author{
SCIENTIFIC PRODUCTION ON OCCUPATIONAL THERAPY:THE SILENCING OF THE \\ WORK-HEALTH RELATIONSHIP
}

LA PRODUCCIÓN CIENTÍFICA SOBRE TERAPIA OCUPACIONAL: EL SILENCIAMIENTO DE LA RELACIÓN TRABAJO-SALUD

\author{
Renata da Silva de Faria ${ }^{1}$ \\ Luiz Carlos Fadel de Vasconcellos ${ }^{2}$ \\ Daniele Masterson Tavares Pereira Ferreira ${ }^{3}$
}

Resumo O objetivo deste trabalho foi conhecer o cenário e construir um panorama geral da produção científica da terapia ocupacional, trabalho e saúde, bem como identificar de que forma tais publicações vêm se configurando em relação à produção do conhecimento, especificamente no desenvolvimento do pensamento empírico e teórico na formação em terapia ocupacional - como estão sendo conduzidas as discussões, com base em quais referenciais teóricos e abordagens metodológicas são orientadas. A pesquisa foi realizada nas bases de dados Pubmed, Lilacs e Cochrane Library, e as categorias analisadas foram: publicações nacionais e internacionais; países de publicação; ano de publicação; tipo de publicação; quais revistas e áreas de concentração; e concentração por tema e assunto. Concluiu-se que o tema necessita de outras discussões teóricas e metodológicas, visando aprofundar a relação entre os campos da terapia ocupacional, trabalho e saúde. Com a aproximação entre os três campos e as relações que se pôde estabelecer entre eles, observou-se que, em sua maioria, a produção nas esferas técnica e acadêmica não considera a complexa relação entre trabalho e saúde.

Palavras-chave terapia ocupacional; saúde; trabalho; saúde do trabalhador; produção científica.
Abstract The aim of this study was to get to know the scenario and build an overview of the scientific production in occupational therapy, work and health, and to identify how such publications have been being set up with regard to the production of knowledge, specifically in the development of empirical thought and in theoretical training in occupational therapy how the discussions are being conducted, and based on which theoretical and methodological approaches references they are guided. The survey was conducted in the Pubmed, Lilacs and Cochrane Library databases, and the categories analyzed were Brazilian and international publications, publishing countries, year of publication, type of publication, magazines and areas of concentration, and concentration by topic and subject. It was concluded that the issue requires further theoretical and methodological discussions aiming to deepen the relationship between the fields of occupational therapy, work and health. With the approximation among the three fields and the relationships that could be established among them, it was observed that, in most cases, production in technical and academic spheres does not take the complex relationship between work and health into account.

Keywords occupational therapy; health; work; worker's health; scientific production. 


\section{Introdução: o campo do pensamento}

O trabalho, a recreação e os exercícios como forma de tratamento e entretenimento são referidos na historiografia médica desde os primórdios da civilização. A terapia ocupacional (TO) iniciou sua intervenção nos anos 1940, com doentes mentais, e na década seguinte com incapacitados físicos, objetivando a remissão dos sintomas patológicos e a reabilitação social e econômica dessa clientela. Para tanto, utilizaram-se o trabalho, a recreação e o exercício como meios de desenvolvimento e adaptação do homem à sociedade. A vinculação dessas três formas de atividade humana, numa abordagem terapêutica em resposta a demandas sociais específicas, constituiu historicamente a terapia ocupacional (Soares, 1991).

No entanto, somente na década de 1990 - período em que a busca pela consistência teórica do campo passou a ser mais significativa - a atividade humana como ocupação foi se sistematizando e se tornando autônoma, separada da prática médica, constituindo-se como ciência da ocupação humana (Lima, Okuma e Pastore, 2013; Magalhães, 2013).

Segundo Francisco (2001), esse movimento teve fortes influências do materialismo histórico, o qual considera que as diferentes formas de produção constituem um modo determinado de atividade e de vida.

A maneira como os indivíduos manifestam a sua vida reflete exatamente o que eles são. O que eles são coincide, pois, com sua produção, isto é, tanto com o que eles produzem quanto com a maneira como produzem. O que os indivíduos são depende, portanto, das condições materiais da sua produção (Marx e Engels, 1999, p. 11).

Entender a 'ocupação' com base no raciocínio terapêutico ocupacional proposto pela American Occupational Therapy Association (2010) pressupõe considerar fatores relacionados ao 'domínio' - ocupação como participação na vida, no cotidiano - e ao 'processo' - implicação entre o terapeuta ocupacional, pessoa, organização ou comunidade na mediação e dialogicidade com as atividades humanas.

Nesse sentido, a terapia ocupacional se constitui como ciência da ocupação humana por entender que a atividade humana, como ocupação nas suas principais áreas de desempenho - atividades diárias, trabalho, lazer e participação social -, faz parte da constituição do sujeito e, portanto, é produtora de processos de saúde e doença. E é por meio do estudo da ocupação humana que o terapeuta ocupacional intervém nesses processos (Pedretti, 2005).

Há na terapia ocupacional uma visão ético-ecológica que entende o sujeito como um ecossistema integrado nas suas ocupações cotidianas. Para tanto, é fundamental entender que a terapia ocupacional se preocupa com 
os fazeres humanos e com as possíveis alterações geradas no cotidiano desses fazeres. E também que as transformações culturais e históricas, processos de sofrimento, adoecimento e de envelhecimento influenciam diretamente no modo como o sujeito se relaciona com o seu fazer, porque ela compreende que as ocupações e as atividades humanas são centrais na constituição e identificação cultural e social do sujeito, que teria, desse modo, uma natureza ocupacional (Medeiros, 2010).

Entretanto, não se pode dizer que há homogeneidade no trato dos conceitos fundantes da profissão; há, sim, alguns consensos que indicam a intenção de se construir uma terapia ocupacional rigorosa no trato do seu objeto, a ocupação humana (Magalhães, 2013).

A discussão sobre a centralidade do 'trabalho' como prática - 'atividade' - e objeto - 'ocupação humana' - aponta para o fato de que em muitas culturas, sobretudo nas sociedades capitalistas contemporâneas, o trabalho é um dos principais determinantes sociais dentre vários aspectos de nossas vidas. Não só pela questão do status social, do trabalho assalariado e das distinções de classe, mas também pela constituição do ser/existir do sujeito no mundo.

Com base nas ideias de Canguilhem (2009) - que considera a interdependência do 'modo de andar a vida' com a autonomia, que implica a possibilidade de reconstrução, pelos sujeitos, dos sentidos de sua vida, e que tal ressignificação teria peso efetivo no seu modo de viver -, o trabalho desempenharia, portanto, um importante papel no 'modo de andar a vida'. Veja-se que aqui o destaque não é exatamente a 'ausência de doença' como garantia da manutenção do trabalho, mas a prerrogativa da escolha, da autonomia e da singularidade dos modos de ser/existir de cada um no cotidianoentendendo o trabalho como a ocupação central na vida humana, em suas perspectivas materiais e simbólicas, na construção potente de sentido.

Hannah Arendt (2007), em seu livro A condição humana, com a expressão vita activa define as três atividades humanas fundamentais: o labor, o trabalho e a ação.

O labor é a atividade que corresponde ao processo biológico do corpo humano (...). A condição humana do labor é a própria vida. O trabalho é a atividade correspondente ao artificialismo da existência humana (...). O trabalho produz um mundo 'artificial' de coisas, nitidamente diferente de qualquer ambiente natural. A condição humana do trabalho é a mundanidade. A ação, única atividade que se exerce diretamente entre os homens sem a mediação das coisas ou da matéria, corresponde à condição humana da pluralidade, ao fato de que homens, e não o Homem, vivem na Terra e habitam o mundo. Todos os aspectos da condição humana têm alguma relação com a política; mas esta pluralidade é especificamente 'a' condição (...) de toda a vida política (Arendt, 2007, p. 15). 
Arendt afirma ainda que

(...) a pluralidade é a condição da ação humana pelo fato de sermos todos os mesmos, isto é, humanos, sem que ninguém seja exatamente igual a qualquer pessoa que tenha existido, exista ou venha a existir. As três atividades e suas respectivas condições têm íntima relação com as condições mais gerais da existência humana (Arendt, 2007, p. 16).

A mesma autora desenvolve a ideia de que a forma de existência predominante no mundo contemporâneo praticamente reduziu todas as atividades que realizamos - em especial a capacidade de produzir obras e realizar ações - ao denominador comum de um labor voltado a assegurar as coisas necessárias à vida do nosso corpo biológico, produzi-las e consumi-las. Essa vida que o labor visa manter se refere ao processo biológico do corpo humano.

O homem reduzido ao labor está aprisionado, segundo Arendt (2007), a uma atividade que se desenvolve de forma cíclica e repetitiva, cujo único objetivo é a produção cada vez maior de coisas pouco duráveis a serem consumidas, e que não termina senão com a exaustão da força de trabalho. Quando tudo que fazemos se resume a esse mecanismo de produção incessante de bens perecíveis e consumo incessante desses mesmos bens, deixamos de construir um mundo e de estar entre os homens como seres políticos e ficamos reduzidos às nossas necessidades privadas.

Nesse contexto, ainda segundo a autora, qualquer 'tempo livre' não dedicado ao trabalho em sua qualidade de labor volta-se para o consumo ou ocupação desse tempo de forma apolítica, automatizada.

Aqui duas questões chamam a atenção no contexto dessa reflexão. A primeira se refere ao entendimento do trabalho única e exclusivamente na perspectiva da atividade produtiva assalariada, em detrimento da concepção de trabalho como atividade política, de criação, expressão e transformação, todas relacionadas à ação. Dessa forma, o trabalho é interpretado na perspectiva do emprego. Já a segunda se refere ao fato de o 'tempo livre', o ócio, ser 'ocupado' por automatismos, pelo não pensar, por atividades sem significados e sentidos - o que nos remete ao conceito reduzido de ocupação.

O trabalho é indispensável à sobrevivência humana e fundamental para a organização social, de modo que a sua reprodução social "é [a] mediação entre o homem e natureza, e dessa interação deriva todo o processo de formação humana" (Marx, 1983, p. 14). É pelo fazer/trabalho que os indivíduos sociais aprendem e desenvolvem sua capacidade criadora, de produção coletiva e reflexiva. O trabalho constitui-se como elemento fundante do ser social, e dessa forma é 'exclusivamente humano'. 
Foi este trabalho consciente que lhe permitiu deixar as cavernas e morar em casas; fabricar e usar móveis, sentar-se à mesa e comer; produzir camas e deitar-se com o companheiro ou companheira e amar, ao invés de só instintivamente sobreviver, comer e possuir. Conquanto mantendo seus instintos básicos de matar para comer e fazer sexo para procriar, ele fez deles, através do trabalho, atos sociais, sociabilizando as suas necessidades. Ao transformar conscientemente a natureza pelo trabalho, se apropriou dela como nenhuma outra espécie viva pôde fazê-lo (Departamento Intersindical de Estudos e Pesquisas de Saúde..., 1989, p. 13).

A categoria trabalho, uma vez compreendida na sua historicidade material e dialética, permite alcançar uma definição de sujeito como sendo aquele que, para ser/existir, necessita produzir os seus próprios meios de subsistência material e simbólica.

Apesar de o trabalho ser anterior à sociedade capitalista e ter tido formas de produção distintas nos diferentes períodos históricos, é a partir do modo de produção capitalista que ele expressa suas maiores contradições. Nele, o trabalho é compreendido como mercadoria, porque toda produção capitalista toma a forma de mercadoria.

Marx (2004) demonstrou que o trabalho, mediador orgânico do homem com a natureza, na sociedade capitalista, é marcado pela alienação e pelo estranhamento. O homem é reduzido à sua condição de força de trabalho, ou seja, mercadoria de troca, barganha, na sociedade salarial. Portanto, o capitalismo transforma o trabalho como forma de 'andar a vida', emancipador, criador e libertador, em força de trabalho, mercadoria, estranhamento, alienação. Em última análise, nesse contexto, trabalho é reduzido a emprego, atividade assalariada.

Esse é um ponto crítico e aponta para questões que estão relacionadas ao processo de precarização, comumente verificadas nos variados tipos de vínculo e contratos nas condições de desemprego estrutural, subemprego, na inclusão irresponsável das pessoas com deficiência no mercado de trabalho empregando-as, mas não as incluindo efetivamente, nos processos de reabilitação e readaptação profissional compulsórios, trabalho informal, escravo, entre outros, e em seus desdobramentos como violência, pobreza, desigualdade, injustiça, sofrimento/adoecimento e morte.

As formas de produção do sistema capitalista transcendem o processo de trabalho, invadem a vida social - ou seja, as relações capitalistas se fazem presentes nas relações sociais, culturais, afetivas, aspectos esses que influenciam diretamente a prática do terapeuta ocupacional, não só no campo do trabalho, mas também no contexto geral do cuidado, ao passo que as questões relacionadas ao trabalho são transversais à saúde e à vida dos sujeitos. 
Nesse sentido, partindo-se do pressuposto de que o homem em atividade e a ocupação humana são objetos de estudo da terapia ocupacional e considerando-as centrais na formação teórico-metodológica e prática desse profissional, buscou-se refletir sobre a seguinte questão: o que a terapia ocupacional vem produzindo nas esferas técnica e acadêmica e de que forma essas publicações vêm se configurando em relação à produção de conhecimento no contexto da terapia ocupacional, trabalho e saúde?

\section{O caminho do pensamento}

O estudo ${ }^{4}$ se propôs a realizar uma revisão sistemática das produções científicas nacionais e internacionais da terapia ocupacional, no contexto trabalho e saúde.

A revisão sistemática, assim como outros tipos de estudo de revisão, é uma forma de pesquisa que utiliza como fonte de dados a literatura sobre determinado tema. Esse tipo de investigação se caracteriza por uma análise minuciosa e pela apresentação objetiva dos achados/resultados por meio de um panorama geral das publicações, mediante a aplicação de métodos explícitos e sistematizados de busca, apreciação crítica e síntese da informação selecionada. Nesse sentido, são particularmente úteis para integrar as informações de um conjunto de estudos realizados separadamente sobre determinada temática, permitindo incorporar um espectro maior de informações que podem ser conflitantes ou coincidentes, bem como identificar temas que necessitam ser mais bem explorados, auxiliando na orientação para investigações futuras (Linde e Willich, 2003).

O método desta pesquisa seguiu as recomendações para a realização de revisões sistemáticas propostas pelas diretrizes metodológicas do Ministério da Saúde (Brasil, 2012), bem como as demais recomendações propostas pelo Cochrane Handbook for Systematic Reviews of Interventions, e pelo Preferred Reporting Items for Systematic Reviews and Meta-Analyses (PRISMA), da Universidade de Oxford. 5

As etapas de pesquisa e protocolo de busca foram elaboradas com base na seguinte organização: definição do objetivo da revisão e das questões que nortearam o estudo; definição dos critérios de inclusão e exclusão dos artigos; definição dos termos, descritores de assunto MeSH (Medical Subject Healding) e DeCS (descritores em ciências da saúde), definição das estratégias de busca e das bases de dados a serem pesquisadas; levantamento dos estudos; seleção dos estudos, avaliação dos títulos e dos resumos (abstracts) identificados na busca inicial; análise da qualidade metodológica dos estudos a partir da validade dos estudos incluídos nela; discussão e análise dos resultados. 
A busca e a recuperação dos artigos foram realizadas de forma abrangente nas principais bases de dados referenciais: Medline/Pubmed, Cochrane Library e Lilacs. As bases foram escolhidas pelo seu caráter multidisciplinar e por entendermos ser enriquecedor efetuar a pesquisa em fontes de informação de várias áreas do conhecimento.

Não foi aplicado filtro de idioma nem de ano de publicação. Dessa forma, todos os trabalhos recuperados foram incluídos. As estratégias foram elaboradas, sempre que possível, utilizando-se o vocabulário controlado de descritores de assunto (Mesh/Medline e DeCS/BVS). Usaram-se também termos livres para todos aqueles termos em que não havia uma representação de assunto no vocabulário controlado.

Os descritores utilizados e os termos livres relacionados para a busca foram: 'Terapia Ocupacional'/'Occupational Therapy', 'Saúde do Trabalhador'/'Occupational Health', 'Medicina do Trabalho'/'Occupational Medicine', 'Serviços de Saúde do Trabalhador'/'Occupational Health Services', 'Política de Saúde do Trabalhador'/'Occupational Health Politics', 'Programa de Saúde do Trabalhador'/'Health Worker Program', 'RENAST', 'CEREST', Trabalho/Work, Trabalhador/Worker* e Emprego/Employment*.

Os recursos de busca como termos truncados $\left({ }^{*}\right)$, os operadores lógicos booleanos or para adição e and para relação dos termos, bem como as diferentes grafias, siglas e termos relacionados, contribuíram para aumentar a sensibilidade das buscas. A busca foi realizada em três principais índices: título, abstract e assunto em todas as bases de dados, pressupondo-se que o título e o resumo revelam o objeto do estudo. As estratégias foram desenhadas de acordo com a especificidade de cada base de dados.

Quando o título e o resumo não eram esclarecedores, buscou-se o artigo na íntegra, para não correr o risco de se deixarem estudos importantes fora da revisão.

Com base nas questões inicialmente relacionadas, a análise dessas publicações buscou apreender as ideias centrais e os principais aspectos apontados nos estudos, tendo sido realizada após a classificação das publicações encontradas e a verificação da adequação aos critérios de inclusão adotados.

O tratamento inicial dado aos materiais selecionados baseou-se no cômputo numérico dos textos segundo as classificações adotadas, de forma a se identificar a ênfase apresentada nos estudos incluídos para análise.

Para a análise qualitativa, utilizamos como referencial a técnica de análise de conteúdo, de acordo com os pressupostos de Bardin (1977). Essa técnica pode ser considerada um "conjunto de técnicas de análise das comunicações e análise dos significados (análise temática), que utiliza procedimentos sistemáticos e objetivos de descrição dos conteúdos das mensagens" (Bardin, 1977, p. 31).

Entretanto, não se pretendeu realizar a aplicação dos métodos e técnica propostos por Bardin. No caso do presente estudo, os materiais foram analisados 
de acordo com as seguintes categorias: publicações nacionais e internacionais; países de publicação; ano de publicação; tipo de publicação; quais revistas e áreas de concentração; concentração por tema e assunto.

A apresentação sistemática dos dados com base nas categorias de análise escolhidas favoreceu a construção de um painel sobre o cenário atual dessas produções científicas e facilitou a identificação dos aspectos mais relevantes sobre a terapia ocupacional, trabalho e saúde.

\section{Olhares da terapia ocupacional sobre o contexto da relação trabalho e saúde}

A soma das bases de dados pesquisadas totalizou 2.446 artigos. Inicialmente, 592 referências foram excluídas por estarem em duplicata. O uso do gerenciador de referências EndNoteWeb ${ }^{6}$ possibilitou a identificação das referências duplicadas e a exclusão de forma confiável. Das 1.854 referências remanescentes, 623 foram selecionadas e 1.204 descartadas de acordo com os critérios de inclusão e exclusão pela leitura de título e resumo. Artigos sugestivos de inclusão, ou que não possuíam resumo, mas títulos sugestivos, passaram pela etapa de avaliação por texto completo. Nesta etapa, das 27 referências analisadas, oito tiveram elegibilidade confirmada pela leitura completa e guiada pelas questões norteadoras. O estudo totalizou 575 artigos (Figura 1).

\section{Figura 1}

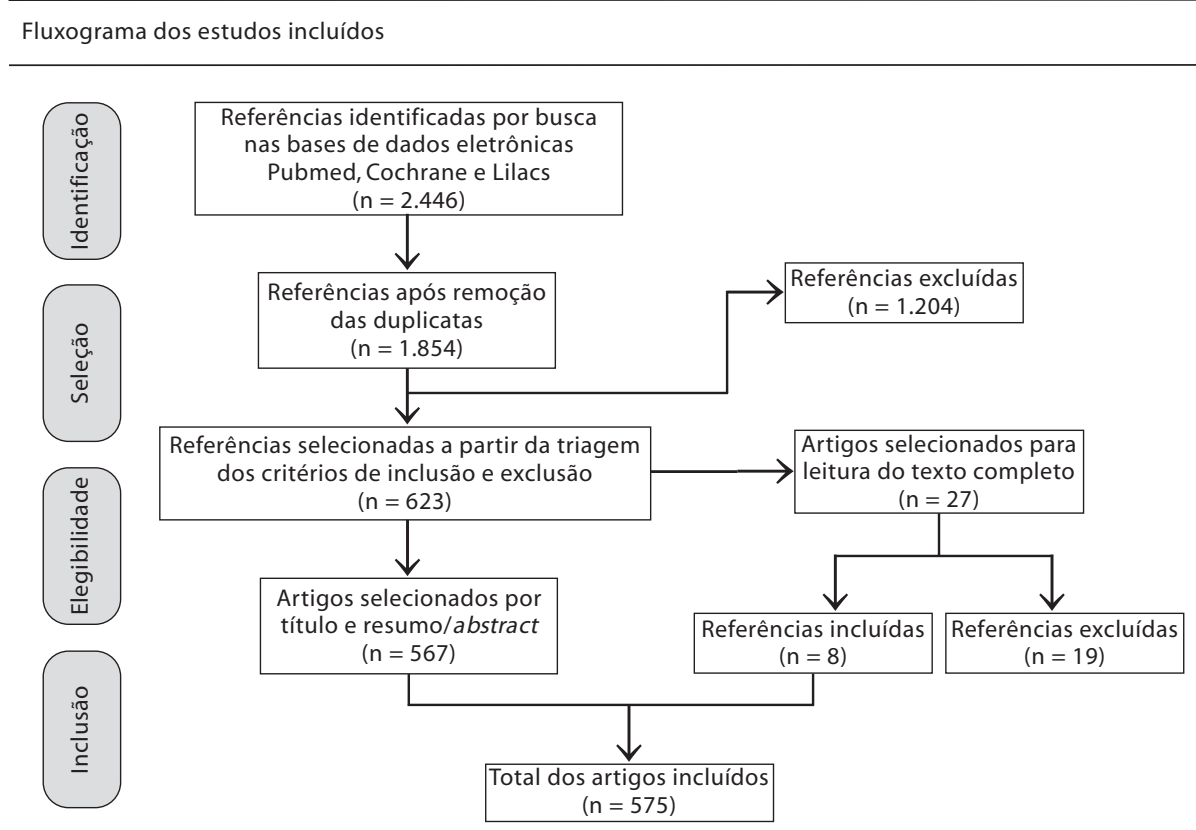

Fonte: Ministério da Saúde, Diretrizes metodológicas, Anexo E: Fluxo de seleção dos artigos da revisão sistemática (Brasil, 2012). 
Do total de 575 publicações referentes à temática, 424 foram obtidas na base de dados Bireme/Pubmed, 24 em The Cochrane Library e 127 na Lilacs. Dentre elas, 121 brasileiras e 454 internacionais, demonstrando que em âmbito internacional a quantidade de publicações é bem maior que no Brasil.

Dentre os países de maior expressão do ponto de vista da quantidade de produções no campo da terapia ocupacional encontram-se os Estados Unidos, a Inglaterra e o Canadá. Tal fato se deve, principalmente, ao alto investimento no campo da produção científica, bem como ao financiamento de pesquisas e criação de revistas e jornais para publicação (Lancman, 2004). Entretanto, com relação à temática do 'trabalho', percebe-se uma produção expressiva de outros países, como Países Baixos e Brasil, que, comparados a países com maior incentivo em pesquisas acadêmicas, apresentam um número de publicações significativo (Tabela 1).

Tabela 1

\begin{tabular}{cc}
\hline País de publicação e participação proporcional & \\
\hline País & Participação (\%) \\
\hline Estados Unidos & $31 \%$ \\
Países Baixos & $16 \%$ \\
Inglaterra & $14 \%$ \\
Brasil & $12 \%$ \\
Canadá & $6 \%$ \\
Austrália & $5 \%$ \\
Itália & $2 \%$ \\
França & $1 \%$ \\
Rússia & $1 \%$ \\
Outros & $12 \%$ \\
\hline
\end{tabular}

Fonte: Os autores.

O número de publicações relacionadas aos países também está associado às revistas/journals de referência para a área. É possível identificar que mais de $60 \%$ das produções científicas nacionais e internacionais são publicadas em revistas/journals de terapia ocupacional, o que consequentemente confere maior número de publicações e periodicidade em países que têm revistas/journals nacionais ou internacionais na área de terapia ocupacional (Tabelas 2 e 3). 
Tabela 2

\begin{tabular}{ccc}
\hline Distribuição por área de concentração e por revista/journa / internacional & \\
\hline Área de concentração & Revista/Journal & Número de publicações \\
\hline Terapia ocupacional & The American Journal of Occupational Therapy & $27 \%$ \\
Trabalho & Work (Reading, Mass) & $18 \%$ \\
Reabilitação em terapia ocupacional & Journal Occupation Rehabilitation & $11 \%$ \\
Terapia ocupacional & Canadian Journal of Occupational Therapy & $8 \%$ \\
Terapia ocupacional & Australian Occupational Therapy Journal & $6 \%$ \\
Terapia ocupacional & Occupational Therapy International & $4 \%$ \\
Medicina do trabalho & $4 \%$
\end{tabular}

Fonte: Os autores.

Tabela 3

\begin{tabular}{ccc}
\hline Distribuição por área de concentração e revista/journal nacional & \\
\hline Area de concentração & Revista/Journal & Número de publicações \\
\hline Terapia ocupacional & Revista de Terapia Ocupacional da Universidade de São Paulo & $32 \%$ \\
Terapia ocupacional & Cadernos de Terapia Ocupacional da Universidade de São Carlos & $24 \%$ \\
Trabalho & Revista Brasileira de Saúde Ocupacional & $18 \%$ \\
Reabilitação, psiquiatria, saúde & Outros & $26 \%$ \\
coletiva, medicina, ortopedia, & & \\
enfermagem & & \\
\hline
\end{tabular}

Fonte: Os autores.

Outro fato curioso foi a diferença de status entre os tipos de publicações nacionais e internacionais. Internacionalmente, os journals - revistas de países estrangeiros que equivalem aos nossos periódicos - são considerados meios potenciais de divulgação e publicação de estudos científicos acadêmicos. Entretanto, constituem-se diferentemente dos nossos periódicos em organização e forma. Os journals se caracterizam pela publicação de artigos menores do que aqueles com que estamos acostumados. Nacionalmente, esse formato de publicação é utilizado para publicações técnicas, o que confere um status diferente das publicações em periódicos nacionais e internacionais para a 
comunidade científica, o que pode ser facilmente verificado em processos seletivos que utilizam avaliação de títulos e currículo com pontuações distintas. Normalmente, periódicos são mais bem avaliados em detrimento das notas técnicas.

Entretanto, na área de terapia ocupacional, os journals, revistas estrangeiras e internacionais ocupam status ainda mais importante e representam os principais veículos de publicação técnico-científicos. Têm grande prestígio acadêmico mundial e são mais bem avaliados dos que os nacionais, o que também colabora para o aumento do número de publicações internacionais (Tabela 4).

Tabela 4

\begin{tabular}{ccc}
\hline Tipo de publicação & & \\
\hline Tipo & Número de publicações internacionais & Número de publicações nacionais \\
\hline Artigo revista/journal & 452 & 105 \\
Monografia & 0 & 2 \\
Dissertação & 1 & 9 \\
Tese & 1 & 5 \\
Total & 454 & 121 \\
\hline
\end{tabular}

Fonte: Os autores.

Ao se analisar o número de publicações por ano, não foi observado nenhum aumento ou diminuição expressiva no cenário internacional que pudesse ter alguma relação com acontecimentos históricos e políticos.

Com referência ao cenário nacional, destaca-se o aumento do número das publicações a partir de 2003, quando a especialidade em saúde do trabalhador passou a ser discutida pelos órgãos de classe (Conselhos Regional e Federal de Fisioterapia e Terapia Ocupacional), e quando a categoria em 2005 começou a fazer parte da equipe multiprofissional dos Centros de Referência em Saúde do Trabalhador, da Rede Nacional de Atenção Integral à Saúde do Trabalhador.

O primeiro registro de artigo publicado, internacionalmente, data de 1950, e o primeiro publicado nacionalmente, de 1999, quase meio século depois. Acredita-se que esse fato está diretamente associado à não existência da regulamentação e formação de profissionais terapeutas ocupacionais no Brasil, que só passam a ser reconhecidos, oficialmente, como uma categoria profissional a partir de 1993.

A publicação de 1950 aborda a temática da avaliação dos trabalhadores que se acidentam/ferem em uma indústria e está entre os cinquenta artigos 
mais citados em produções científicas internacionais, segundo sistematização dos dados no EndNoteWeb. É considerada uma referência ainda atual com relação à abordagem metodológica, aos apontamentos realizados e aos resultados apresentados.

Podemos observar também que a partir dos anos 2000 o número de publicações da terapia ocupacional vem apresentando um crescimento, tanto no cenário internacional quanto no nacional, o que é representativo na perspectiva da produção do conhecimento.

Dos 575 artigos encontrados nesta pesquisa, ao se considerar a média de publicação por ano, temos em média sete artigos internacionais e oito nacionais, o que representa um número bastante significativo em comparação a outros países e, de certo modo, expressa o crescimento sinalizado anteriormente (Tabela 5).

Tabela 5

\begin{tabular}{|c|c|c|c|c|c|c|c|c|c|c|}
\hline \multicolumn{11}{|c|}{ Número de publicações nacionais e internacionais por ano } \\
\hline \multicolumn{10}{|c|}{ Linha do tempo de 1950 a 2013} & \\
\hline 1950 & 1951 & 1952 & 1953 & 1954 & 1955 & 1956 & 1957 & 1958 & 1959 & \\
\hline 4 & 3 & 1 & 0 & 5 & 4 & 1 & 1 & 2 & 3 & \\
\hline 1960 & 1961 & 1962 & 1963 & 1964 & 1965 & 1966 & 1967 & 1968 & 1969 & \\
\hline 4 & 5 & 10 & 2 & 19 & 13 & 6 & 5 & 2 & 5 & \\
\hline 1970 & 1971 & 1972 & 1973 & 1974 & 1975 & 1976 & 1977 & 1978 & 1979 & \\
\hline 5 & 7 & 3 & 1 & 1 & 2 & 3 & 1 & 0 & 2 & \\
\hline 1980 & 1981 & 1982 & 1983 & 1984 & 1985 & 1986 & 1987 & 1988 & 1989 & \\
\hline 0 & 0 & 1 & 2 & 0 & 14 & 6 & 2 & 2 & 3 & Publicações internacionais \\
\hline 1990 & 1991 & 1992 & 1993 & 1994 & 1995 & 1996 & 1997 & 1998 & 1999 & Publicações nacionais \\
\hline 4 & 2 & 7 & 3 & 4 & 3 & 5 & 2 & 2 & 6 & \\
\hline- & - & - & - & - & - & - & - & - & 1 & \\
\hline 2000 & 2001 & 2002 & 2003 & 2004 & 2005 & 2006 & 2007 & 2008 & 2009 & \\
\hline 8 & 8 & 11 & 2 & 13 & 13 & 17 & 21 & 28 & 30 & \\
\hline 3 & 5 & 7 & 9 & 10 & 12 & 10 & 6 & 7 & 7 & \\
\hline 2010 & 2011 & 2012 & 2013 & - & - & - & - & - & - & \\
\hline 29 & 27 & 33 & 26 & - & - & - & - & - & - & \\
\hline 8 & 9 & 10 & 13 & - & - & - & - & - & - & \\
\hline
\end{tabular}

Fonte: Os autores. 
Na diversidade desses estudos podem ser encontrados diferentes eixos de conexão entre terapia ocupacional, trabalho e saúde. Ao se utilizar a análise de conteúdo como referência, identificaram-se as principais discussões teóricas travadas pelo campo da terapia ocupacional, mais especificamente nas áreas de concentração de tema e assunto teóricos e práticos que subsidiam o olhar sobre as produções científicas.

Nesse sentido, é possível observar que os cenários nacional e internacional coincidem em relação às principais áreas temáticas e proporção do número de publicações no contexto trabalho e saúde. Consequentemente, acreditamos que as produções internacionais influenciaram e influenciam as nacionais, ao passo que durante quase cinquenta anos foram as únicas referências na construção do campo teórico e prático e que ainda hoje são amplamente citadas em estudos nacionais (Tabela 6).

Tabela 6

\begin{tabular}{cccc}
\hline Concentração por tema e assunto & & & \\
\hline Concentração por tema e assunto & Número de publicaçöes internacionais & Número de publicaçōes nacionais & Total \\
\hline Reabilitação e readaptação profissional & 169 & 37 & 206 \\
Doenças ocupacionais (LER/Dort) & 73 & 21 & 94 \\
Inclusão no mercado de trabalho & 62 & 18 & 63 \\
Saúde mental e trabalho & 47 & 16 & 38 \\
Terapia trabalho & 31 & 7 & 20 \\
Emprego apoiado & 19 & 1 & 23 \\
Ergonomia & 18 & 5 & 9 \\
Outros & 0 & 9 & 7 \\
Total & 35 & 121 & 575 \\
\hline
\end{tabular}

Fonte: Os autores.

Nota:LER - Lesão por Esforço Repetitivo; Dort - Distúrbio Osteomuscular Relacionado ao Trabalho.

Os resultados da revisão sistemática demonstraram a predominância de estudos na área de reabilitação e readaptação profissional, que correspondem a um total de 206 estudos, cerca de 35\% do número total de publicações. Esse é um espelho da formação teórica e prática do terapeuta ocupacional. A reabilitação ainda representa o potencial simbólico de maior expressão e representatividade da categoria, mesmo com o 'novo' paradigma do conceito ampliado de saúde e com algumas iniciativas potentes no ponto de vista da transformação, no sentido de ocupar outros espaços, campos e especialidades e de agregar novos valores à profissão. 
A segunda grande proporção de estudos é oriunda de uma das principais subáreas da reabilitação no contexto do trabalho, as doenças ocupacionais, mais especificamente as tráumato-ortopédicas - lesões por esforço repetitivo e outras doenças ocupacionais relacionadas ao trabalho -, que, com enfoques e tipos de estudos variados, apresentaram 94 publicações.

O terceiro eixo trata da discussão da inclusão no mercado de trabalho e tangencia, principalmente, as questões relacionadas às pessoas com deficiência. São estudos, em sua maioria, com formatos de relato de experiência e estudos de caso.

Saúde mental e trabalho também são temas bastante pesquisados pela categoria. Representa o quarto eixo mais explorado, com 67 publicações. Podemos considerar que esse bloco temático é um dos mais diversificados em relação aos outros, o que corresponde a uma característica própria do entendimento singular por parte dos profissionais com relação a problemas, doenças, transtornos mentais e suas respectivas atuações com os sujeitos de intervenção nesse campo.

Em quinto lugar está o tema terapia do trabalho, que não é uma abordagem recente na literatura da terapia ocupacional. Significa utilizar a atividade que gera um produto e que tenha, além do valor de uso, um valor de troca como ferramenta terapêutica (Francisco, 2001). Essa prática é mais difundida nos Estados Unidos e no Canadá. No Brasil, as discussões mais recentes têm caminhado na direção da economia solidária, associativismo e cooperativismo.

Em seguida, estão os artigos relacionados ao emprego apoiado, que surgiu nos Estados Unidos como uma metodologia para inserção de pessoas com deficiência no mercado de trabalho formal, assim como de outros grupos sociais em situação de exclusão social ou com dificuldades particulares para encontrar emprego e de nele se manter. São eles os pioneiros nessa metodologia e, consequentemente, responsáveis por $70 \%$ das publicações internacionais, o que representa 13 artigos do total de vinte publicados.

Segundo o Instituto de Tecnologia Social do Brasil (2001), a metodologia foi incluída pela Revista de Inovação Social, de Stanford, como uma das 'dez recentes inovações sociais'. Observa-se, dessa forma, uma valorização crescente do emprego apoiado em todo o mundo.

Dados o enorme contingente de pessoas com deficiência no Brasil e a baixa taxa de participação no mercado de trabalho das pessoas com deficiência em idade ativa, a Secretaria de Ciência e Tecnologia para Inclusão Social do Ministério da Ciência, Tecnologia e Inovação (Secis/MCTI) tem promovido cursos de formação para os profissionais da saúde que atuam nessa área, apostando que essa estratégia pode garantir a inserção desses grupos no mercado de trabalho. Entretanto, o emprego apoiado tem sido amplamente discutido em fóruns, encontros e seminários sobre terapia ocupacional e trabalho e divide a opinião dos profissionais que atuam nesse campo. 
O penúltimo tema relacionado é a ergonomia, com 23 publicações. A terapia ocupacional utiliza a ergonomia como subsídio em algumas atuações e intervenções no campo do trabalho, apropriando-se da análise ergonômica do trabalho (AET). A AET é um método de estudo do trabalho, e a ergonomia é uma disciplina que estuda o trabalho. Como disciplina, a ergonomia pode usar vários métodos, inclusive a AET. Como método, a AET pode ser utilizada por diferentes disciplinas, inclusive a terapia ocupacional (Watanabe e Gonçalves, 2004).

Esse método de análise tem como objetivo descrever a atividade de trabalho segundo a visão crítica daquele que o executa, ressaltando os princípios da análise na situação real, diferenciando o trabalho real do prescrito e considerando os mais diversos fatores relacionados à organização do trabalho, condições do ambiente, carga física e mental, entre tantos outros (Simonelli e Rodrigues, 2013).

O método prevê a realização de uma análise da demanda, da tarefa, da atividade e de recomendações ergonômicas, a fim de propor melhorias às demandas identificadas. A análise da demanda consiste na contextualização do projeto ante a realidade da demandante; a análise da tarefa, no estabelecimento do conjunto de condicionantes que atuam sobre as situações de trabalho e de uso na unidade produtiva em estudo; e a análise da atividade, no estabelecimento dos aspectos determinantes das situações de trabalho em uso.

O sétimo e último tema está relacionado à saúde coletiva. Não foram encontrados estudos internacionais na área, o que aponta para a questão ideológica da luta pelo sistema público de saúde no Brasil. Entretanto, nacionalmente, a quantidade de estudos ainda é tímida, apenas nove artigos. Estes focalizam a terapia ocupacional e a saúde do trabalhador com intervenção ampliada do profissional nas ações e nos serviços especializados e práticas desenvolvidas na Rede Nacional de Atenção Integral à Saúde do Trabalhador, nos Centros de Referência em Saúde do Trabalhador. Apresentam experiências e pesquisas aplicadas, expõem perspectivas sobre a rede municipal de saúde do trabalhador - interdisciplinaridade e interinstitucionalidade; prevenção de acidentes e doenças; vigilância em saúde do trabalhador. Indicam ainda a atuação em outros setores da seguridade social - assistência e previdência, como, por exemplo, o Instituto Nacional do Seguro Social (INSS).

Na categoria 'outros' estão 42 publicações que, conjuntamente, não representam uma categoria homogênea de estudos e apenas tangenciam o tema 'trabalho e saúde'. Os artigos aqui analisados são diversos e compreendem estudos relacionados a psicodinâmica do trabalho, clínica da atividade, experiências de cooperação técnica, algumas propostas metodológicas de análise e organização do processo de trabalho por meio da organização da rotina das atividades e outras experiências e análises empíricas, construídas juntamente com os trabalhadores. 
Segundo Lancman (2004), existem muitas pesquisas e intervenções em terapia ocupacional que visam aprimorar a produção, as condições e a organização do trabalho, porém escassas são as pesquisas e intervenções que exploram o conteúdo do trabalho, as relações particulares do trabalhador com sua atividade, consternação e desgaste advindos do trabalho e seus efeitos sobre a saúde daqueles que trabalham. Estudos que exploram novos campos contribuem para o aprimoramento do trabalho do terapeuta ocupacional no contexto do trabalho e saúde e apontam para a necessidade da construção de novos olhares.

\section{Considerações, reflexões e apontamentos futuros}

Na revisão sistemática realizada, encontramos algumas evidências que apresentam as relações da terapia ocupacional no contexto trabalho e saúde. Entretanto, grande parte dos estudos emprega o sentido do trabalho do ponto de vista da sua centralidade como produção de vida e constituição do ser/existir homem de forma reducionista.

Alguns estudos acadêmicos, inclusive, apontam para essa direção, considerando como 'trabalho' aquelas atividades que inserem o sujeito em uma prática produtiva assalariada. E ainda que, na perspectiva do avesso, trabalho não é emprego. Para uma reflexão mais profunda, que considere a complexidade dos sentidos do trabalho, é fundamental nos questionarmos: que trabalho é esse? De que atividades estamos falando? De que forma o homem se ocupa do trabalho? Essas questões precedem o entendimento do trabalho como atividade central para a ocupação humana.

É possível, por um lado, identificar fragilidades fundamentais na perspectiva epistemológica da terapia ocupacional como ciência da ocupação humana e da sua identidade, sem aprofundamentos críticos, reflexivos e teóricos, principalmente em sua categoria central: ocupação humana. Por outro lado, encontramos de maneira aprofundada e refinada as mais diversas práticas de reabilitação, inclusão e terapias que utilizam o trabalho como atividade e forma de cuidado. O estado da arte e das práticas da terapia ocupacional no contexto de trabalho e saúde demonstra um investimento na intervenção junto ao sujeito, com o objetivo primeiro de inserir, reinserir, adaptar, readaptar, habilitar e reabilitar para o mercado de trabalho, respondendo a uma lógica contratual capitalista de um trabalho pouco autônomo e emancipatório, alienado e apolítico na perspectiva da criação.

O 'trabalho' como modo de andar a vida demonstra que o tema necessita de outras discussões teóricas e metodológicas, visando aprofundar a relação entre os campos da terapia ocupacional, trabalho e saúde. Nesse sentido, a partir da aproximação entre os três campos e das relações que se pôde estabelecer 
entre eles, observou-se que, em sua maioria, a produção nas esferas técnica e acadêmica não considera a complexa relação entre trabalho e saúde. Esse caráter pouco integrador inviabiliza a compreensão das perspectivas sistêmicas em saúde e da relação trabalho e saúde, o que implica preconizar a resolução de 'problemas' mediante a individualização do cuidado, em detrimento de questões que são vivenciadas, experimentadas e compartilhadas coletivamente.

Com base nesse panorama geral sobre a produção científica da terapia ocupacional, espera-se que esta pesquisa possa subsidiar e fomentar a elaboração de novos estudos críticos, reflexivos e integradores, nas perspectivas intra e intersetoriais e, também, multi, inter e transdisciplinares, na tentativa de tensionar e provocar debates sobre a construção de novos olhares da terapia ocupacional sobre as práticas no cuidado em saúde. Nesse sentido, este estudo aponta para a necessidade de ampliação do diálogo no contexto da relação trabalho e saúde com múltiplas esferas de produção de conhecimentos, saberes, campo de práticas, de ações e serviços: cultural, físico, social, pessoal, espiritual, temporal, virtual - em última análise - de saúde.

Compreender o objeto central da terapia ocupacional, o fazer - 'ocupação humana' - sob o prisma do trabalho, como princípio educativo, no contexto sociopolítico, permite superar as fragilidades conceituais e epistemológicas na formação em terapia ocupacional. Nessa linha, a realização de pesquisas empíricas, cuja abordagem contemple variações sobre a relação trabalho-saúde, poderá trazer à luz distintas questões, tais como vulnerabilidades socioambientais, vínculos precários, cargas e riscos com seus consequentes acidentes e doenças ocupacionais, trabalho infantil, desigualdades de gênero e, entre outras, as novas formas de sofrimento humano pela opressão do trabalho.

Desse modo, a construção de novos caminhos e olhares da terapia ocupacional voltada para uma prática mais integradora dos cuidados em saúde se configura, na verdade, como um desejo e uma proposta de transformação de cenários e práticas que envolvem a compreensão de que condições elementares que sustentam a existência humana, como trabalho, renda, moradia, alimentação, transporte e lazer, são seus determinantes e condicionantes.

\section{Colaboradores}

Renata da Silva de Faria concebeu a proposta e elaborou o texto. Luiz Carlos Fadel de Vasconcellos efetuou a adequação dos objetivos e a revisão do texto. Daniele Masterson Tavares Pereira Ferreira auxiliou na formulação e desenvolvimento da metodologia. 
Resumen El objetivo de este trabajo fue conocer el escenario y construir un panorama general de la producción científica de la terapia ocupacional, trabajo y salud, así como identificar de qué forma tales publicaciones se están configurando con relación a la producción del conocimiento, específicamente en el desarrollo del pensamiento empírico y teórico en la formación en terapia ocupacional - cómo se están conduciendo las discusiones, en base a cuáles referencias teóricas y enfoques metodológicos están orientadas. La investigación se realizó en las bases de datos Pubmed, Lilacs y Cochrane Library, y las categorías analizadas fueron: publicaciones nacionales e internacionales; países de publicación; año de publicación; tipo de publicación; cuáles revistas y áreas de concentración; y concentración por tema y asunto. Se concluyó que el tema necesita otras discusiones teóricas y metodológicas, buscando profundizar la relación entre los campos de la terapia ocupacional, trabajo y salud. Con la aproximación entre los tres campos y las relaciones que se pudo establecer entre ellos, se observó que, en su mayoría, la producción en las esferas técnica y académica no considera la compleja relación entre trabajo y salud.

Palabras clave terapia ocupacional; salud; trabajo; salud del trabajador; producción científica.

\section{Notas}

1 Universidade Federal do Rio de Janeiro, Faculdade de Medicina, Departamento de Terapia Ocupacional.

<refariato@gmail.com>

Correspondência: Universidade Federal do Rio de Janeiro, Departamento de Terapia Ocupacional, Centro de Ciências da Saúde, Bloco K, sala K49, Cidade Universitária, CEP 21941-971, Rio de Janeiro, RJ, Brasil.

2 Fundação Oswaldo Cruz, Escola Nacional de Saúde Pública Sergio Arouca, Rio de Janeiro, RJ, Brasil.

$<$ elfadel@globo.com>

3 Universidade Federal do Rio de Janeiro, Centro de Ciências da Saúde, Rio de Janeiro, RJ, Brasil.

$<$ daniele.masterson@ccsdecania.ufrj.br>

4 Este artigo é parte da pesquisa da dissertação de mestrado intitulada Trabalho: de que atividade/ocupação estamos falando? Um estudo sobre a produção científica da terapia ocupacional, trabalho e saúde, de autoria de Renata da Silva de Faria, sob a orientação de Luiz Carlos Fadel de Vasconcellos, apresentada à Escola Nacional de Saúde Pública Sergio Arouca (Ensp) da Fundação Oswaldo Cruz (Fiocruz), no Rio de Janeiro, em 2013. Está disponível em: <http://search.bvsalud.org/cvsp/resource/pt/lil-714037>.

5 O PRISMA é uma diretriz que tem como objetivo ajudar autores a melhorarem a qualidade do relato dos dados da revisão sistemática.

6 O EndNoteWeb é um serviço via web projetado para auxiliar no processo de elaboração de pesquisas científicas. Possibilita reunir e organizar, rápida e facilmente, informações de referência de uma ampla variedade de fontes e bases de dados. Armazena até dez mil referências que podem ser compartilhadas com outros usuários. 


\section{Referências}

AMERICAN OCCUPATIONAL THERAPY ASSOCIATION (AOTA). Estrutura da prática da terapia ocupacional: domínio e processo. Revista Triângulo: Ensino Pesquisa e Extensão, Uberaba, v. 3, n. 2, p. 57-147, jul./dez. 2010.

ARENDT, Hannah. A condição humana. Rio de Janeiro: Forense Universitária, 2007.

BARDIN, Laurence. Análise de conteúdo. Lisboa: Edições 70, 1977.

DEPARTAMENTO INTERSINDICAL DE ESTUDOS E PESQUISAS DE SAÚDE E DOS AMBIENTES DO TRABALHO (Diesat). Insalubridade: morte lenta no trabalho. São Paulo: Oboré, 1989.

BRASIL. Ministério da Saúde. Secretaria de Ciência, Tecnologia e Insumos Estratégicos. Departamento de Ciência e Tecnologia. Diretrizes metodológicas: elaboração de revisão sistemática e metanálise de ensaios clínicos randomizados. Brasília: Ministério da Saúde, 2012.

CANGUILHEM, Georges. O normal e o patológico. 6. ed. São Paulo: Forense Universitária, 2009.

FRANCISCO, Berenice R. Terapia ocupacional. 2. ed. Campinas: Papirus, 2001.

INSTITUTO DE TECNOLOGIA SOCIAL DO BRASIL (ITS BRASIL). O que é emprego apoiado?. 2001. Disponível em: <www.itsbrasil. org.br/lo-seminario-ea/o-que-e-empregoapoiado>. Acesso em: 22 nov. 2013.

LANCMAN, Selma. Construção de novas teorias e práticas em terapia ocupacional, saúde e trabalho. In: LANCMAN, Selma (org.). Saúde, trabalho e terapia ocupacional. São Paulo: Roca, 2004.

LIMA, Elizabeth M. F. A.; OKUMA, Danielle G.; PASTORE, Marina N. Cadernos de Terapia Ocupacional da UFSCar, São Carlos, v. 21, n. 2, p. 243-254, 2013.
LINDE, Klaus; WILLICH, Stefan N. How objective are systematic reviews? Differences between reviews on complementary medicine. Journal of Royal Society Medicine, Thousand Oaks, v. 96, n. 3, p. 17-22, 2003.

MAGALHÃES, Lilian. Ocupação e atividade: tendências e tensões conceituais na literatura anglófona da terapia ocupacional e da ciência ocupacional. Cadernos de Terapia Ocupacional da UFSCar, São Carlos, v. 21, n. 2, p. $255-263,2013$.

MARX, Karl. O capital: crítica da economia política. São Paulo: Abril Cultural, 1983.

MARX, Karl. Manuscritos econômico-filosóficos. São Paulo: Boitempo, 2004.

MARX, Karl; ENGELS, Friedrich. A ideologia alemã. São Paulo: Martins Fontes, 1998. Disponível em: <www.usp.br/cje/anexos/ pierre/aideologiaalema_karlmarx_e_engels. pdf>. Acesso em: 22 nov. 2013.

MEDEIROS, Maria H. R. Terapia ocupacional: um enfoque epistemológico e social. São Carlos: EdUFSCar, 2010.

PEDRETTI, Lorraine W.; EARLY, Mary B. Terapia ocupacional: capacidades práticas para as disfunções físicas. 5. ed. São Paulo: Roca, 2005.

SIMONELLI, Angela P.; RODRIGUES, Daniela S. (orgs.). Saúde e trabalho em debate: velhas questões, novas perspectivas. Brasília: Paralelo 15, 2013.

SOARES, Léa B. T. Terapia ocupacional: lógica do capital ou do trabalho? Retrospectiva histórica da profissão no Estado brasileiro de 1950 a 1980. São Paulo: Hucitec, 1991.

THE COCHRANE. Cochrane Collaboration. Cochrane Handbook for Systematic Reviews of Interventions, 2011. Disponível em: <http:// handbook.cochrane.org $>$. Acesso em: 11 dez. 2013 
WATANABE, Marisol; GONÇALVES, Rita M.

A. Relações conceituais entre terapia ocupacional e ergonomia. In: LANCMAN, Selma (org.). Saúde, trabalho e terapia ocupacional. São Paulo: Roca, 2004. p. 19-70.

Recebido em 22/04/2014

Aprovado em 08/04/2015 